\title{
Quality Physical Education in Primary Schools from the Teachers' Point of View
}

\author{
Dana Masaryková*, LenkaBobocká \\ Trnava university in Trnava, Faculty of Education, Priemyselná 4, 91843 Trnava, Slovakia
}

*Corresponding Author: Dana Masaryková, Trnava university in Trnava, Faculty of Education, Priemvselná 4. 91843 Trnava. Slovakia

\begin{abstract}
Nowadays, the quality of physical education is a frequently discussed topic and depends on many factors which can influence it considerably: from education programs, through time allocation, quality of teachers, spatial and material provisions etc. This article is aimed at quality physical education factors and their perception by physical education teachers in primary schools. We used a non-standard questionnaire to get information about the quality factors in physical education. Together 67 teachers participated in our research. We found that the teachers' active participation in physical activities is a significant factor in terms of understanding the importance of quality physical education $(p<0,05)$. On the other hand all the teachers participating in our research considered physical education as an important subject, however they concluded that the level of implemented quality physical education is rather average.
\end{abstract}

Keywords: quality physical education, primary schools, physical education teachers, physical activity

\section{INTRODUCTION}

The importance of physical activity is highlighted in every professional discussion focused on healthy lifestyle, physical education or sport. Physical inactivity has been linked with chronic disease and obesity in most western populations. However, a prevalence of inactivity, health beliefs, and knowledge of the risks of inactivity have rarely been assessed across a wide range of developed and developing countries [6]. Physical education is considered as the only subject crucial for motor development of children as well as supporting healthy lifestyle. The current research shows that $70 \%$ of children spend more than 4 hours per day with electronic devices and many of them perform regular activity only during PE lessons in schools [1]. Therefore the importance of quality physical education is even higher. General problems of physical education as a subject that is not appropriately acknowledged in education process usually cover the number of teaching hours, specific content, quality of teacher education and others. Hardman [4] names some of the problems that physical education encounters these days: number of teaching hours, various contents, a large gap between official policies and regulations and real practice, exemption practice from physical education classes etc. According to Haag [3], physical education is currently understood as a ,service "from three basic points of view: medical-natural, social-behavioral and political-economical. Despite the fact that the various research findings prove the importance of $\mathrm{PE}$ for developing regular physical activity, there has not been done enough to improve the situation. It is known that physical activity affects also quality of life. There are some factors e.g. self-esteem, self-efficacy or self - enhancement that can indirectly show this relation. As Rodney et.al [7] state in their findings, health education programmes, as well as physical education can promote importance of physical activity and thus develop healthy lifestyle specifically in primary education.

Physical education in school is essential component for a balanced development of the motor factors, psycho-emotional and social aspects of a child and promotion of physically active lifestyle [2,5]. The physical education delivery in primary schools is usually either through generalist teachers (teaching all subjects in primary level), specialist teachers (teaching only PE) or sport coaches. Most of the European countries have the generalist teachers responsible for teaching PE. The teachers however, encounter various problems affecting the quality of physical education lessons. Important factor is the physical education teacher education which plays an important role [8]. Generally, if we want to 
produce better quality of physical education in schools, the teachers play an essential role. Thus, it is important to examine their perception of quality physical education in their schools.

\section{Materials AND MethodS}

The generalist teachers teaching primary physical education participated in the research $(n=67)$. The average age of teachers was 39.5 years and $97 \%$ of them were women and $3 \%$ men. The data were collected by a questionnaire with open, semi-open and closed questions to receive information about the teachers' opinionsto quality physical education in primary schools. The data obtained by means of a questionnaire were firstly organized and sorted in MS Excel. We used graphs with percentage for presenting all the data related to questionnaire items. We used non-parametric Chi-square test for stating significant relations among the data.

\section{RESULTS AND DISCUSSION}

The questions in the questionnaire were aimed at receiving teachers' opinions on the various factors determining quality physical education. Generally, 54\% of teachers answered that they think the level of quality in physical education is around average and 5\% answered it is not sufficient. On the other hand, $34 \%$ of teachers believe the level of quality of physical education classes is good and $7 \%$ think it is very good (fig. 1).

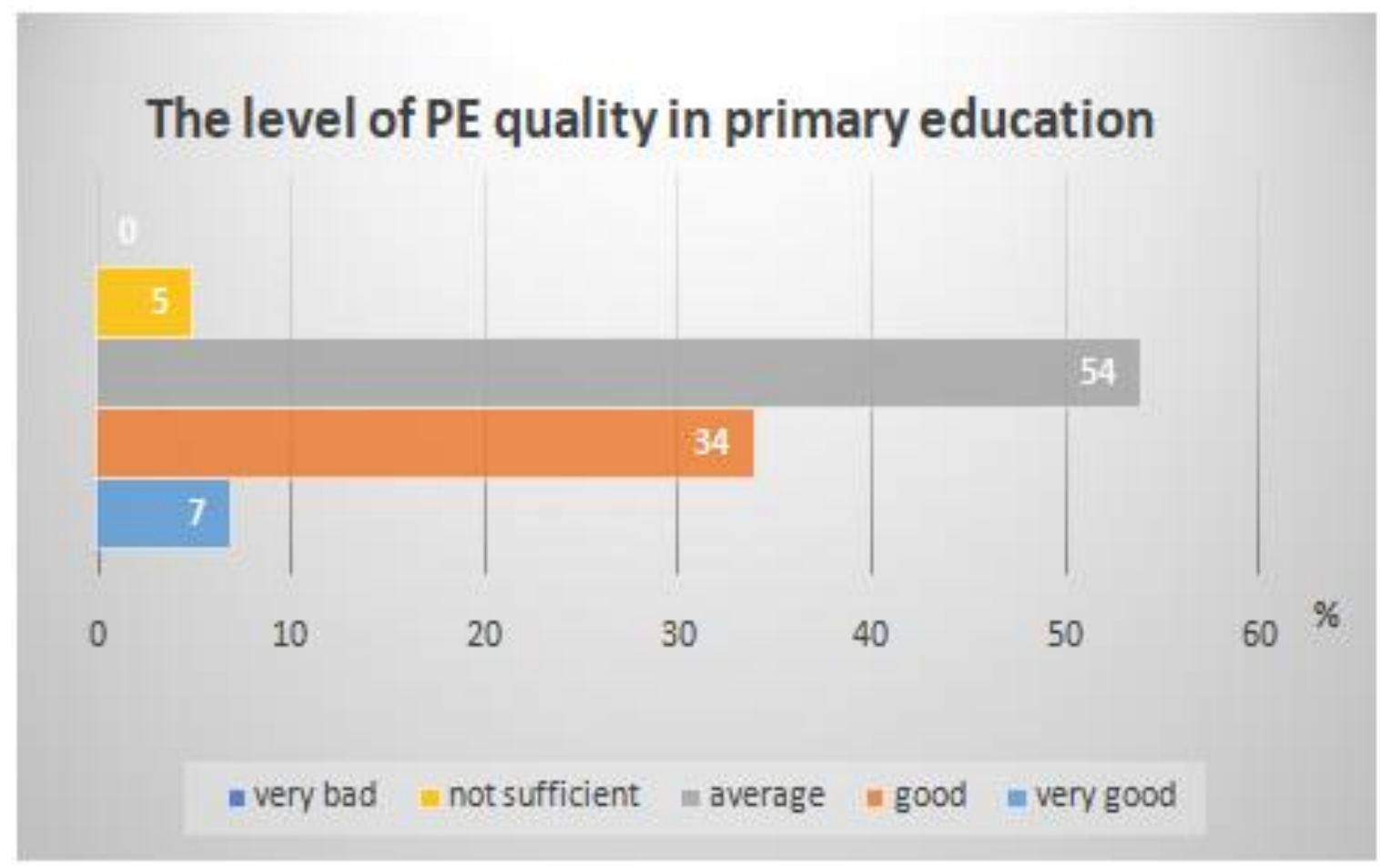

Fig1. The teachers' opinion on the PE quality in primary education

The qualification level in Slovakia to teach in primary schools is a master degree in education. Despite this level of education, 19\% of teachers expressed they are not prepared to teach physical education and they do not feel competent in this area. The curriculum and time allocation are significant factors influencing the level of quality physical education. In the research group $78 \%$ of teachers answered they are satisfied with the curriculum content and $22 \%$ are rather satisfied. There were not complaints or negative answers with respect to the curriculum. The time allocation is increased in favour of physical education in $25 \%$ of schools from the research sample. This is possible due to school education programmes, where the school management can choose subjects where they want to strengthen the number of hours taught during a week. The recommended teaching time for physical education is 2 hours per week, with strong recommendation to increase this amount to 3 hours per week. However, only few schools increase the number of physical education in practice. One of the very crucial factors influencing quality physical education, especially when it is taught by generalist teachers, are replacements or cancelling of PE lessons. The generalist teachers often replace the PE lesson by other subject due to various reasons. $45 \%$ of teachers admitted that they replace PE lesson for other subject because they consider mathematics or languages as more important. It was 
surprising that almost $10 \%$ cancel PE lesson, because they want to punish the pupils for bad behaviour. The PE lesson is mostly the most favourite subject of pupils and therefore this punishment is seen by the teachers as a good choice (fig. 2).

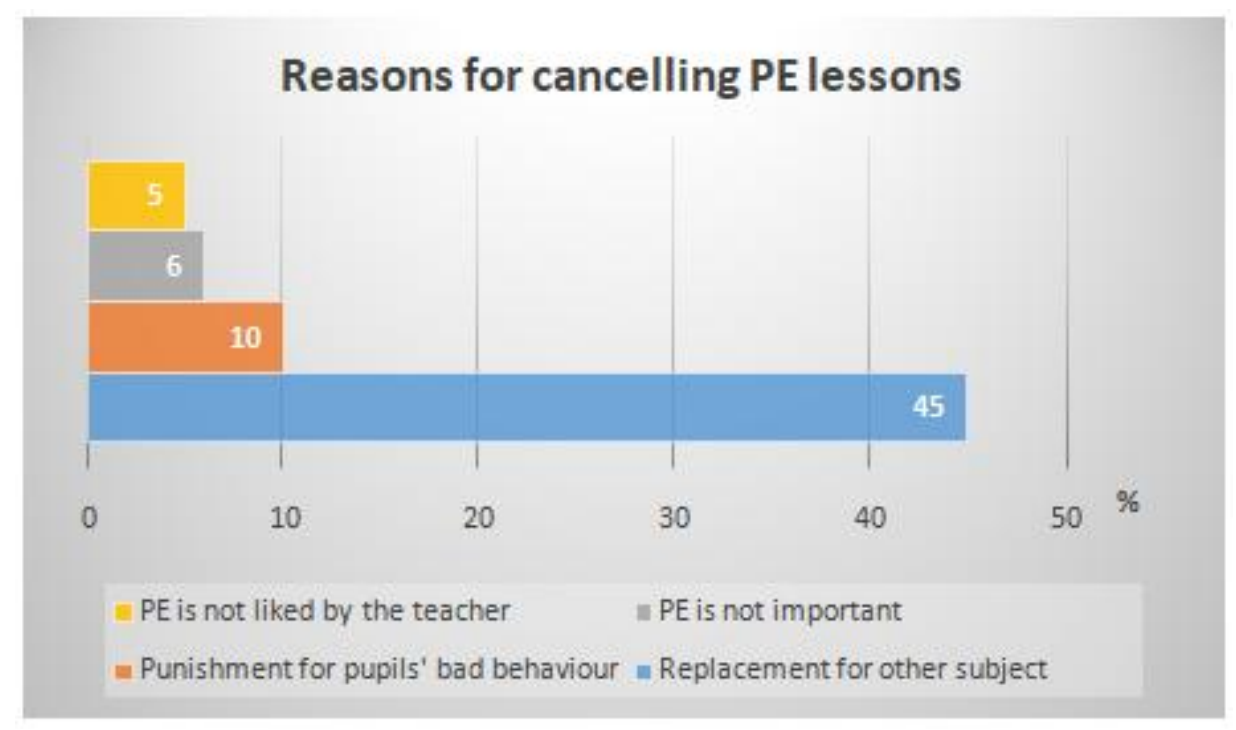

Fig2. Reasons for cancelling PE lessons by the teachers

The material and spatial conditions were also reflected by the teachers. Almost $30 \%$ of teachers consider these conditions in their schools as not sufficient and they think it can influence the quality of PE lessons. The assessment or diagnostics of motor development of children is seen by $24 \%$ of teachers as not important. These teachers believe that assessment in PE is only waste of time (13\%), is not objective $(9 \%)$ or the teachers are not able to do it $(3 \%)$. Finally, we wanted the teachers to express their attitude to sports or physical activity, as it was proved in other scientific works that teachers with better sports background deliver better quality of physical education lessons. Only $22 \%$ of teachers perform regular physical activity and $47 \%$ of teachers answered to practice physical activity only rarely. This attitude to practicing physical activity in teachers' lives can have a negative impact on provision of $\mathrm{PE}$ lessons, as the teacher needs to be more committed in terms of understanding the importance of physical activity as a part of healthy life style and health related fitness (fig. 3). There was found a significant relationship between the physical activity of teachers and the reasons for cancelling the PE lessons $(\mathrm{p}<0,05)$.

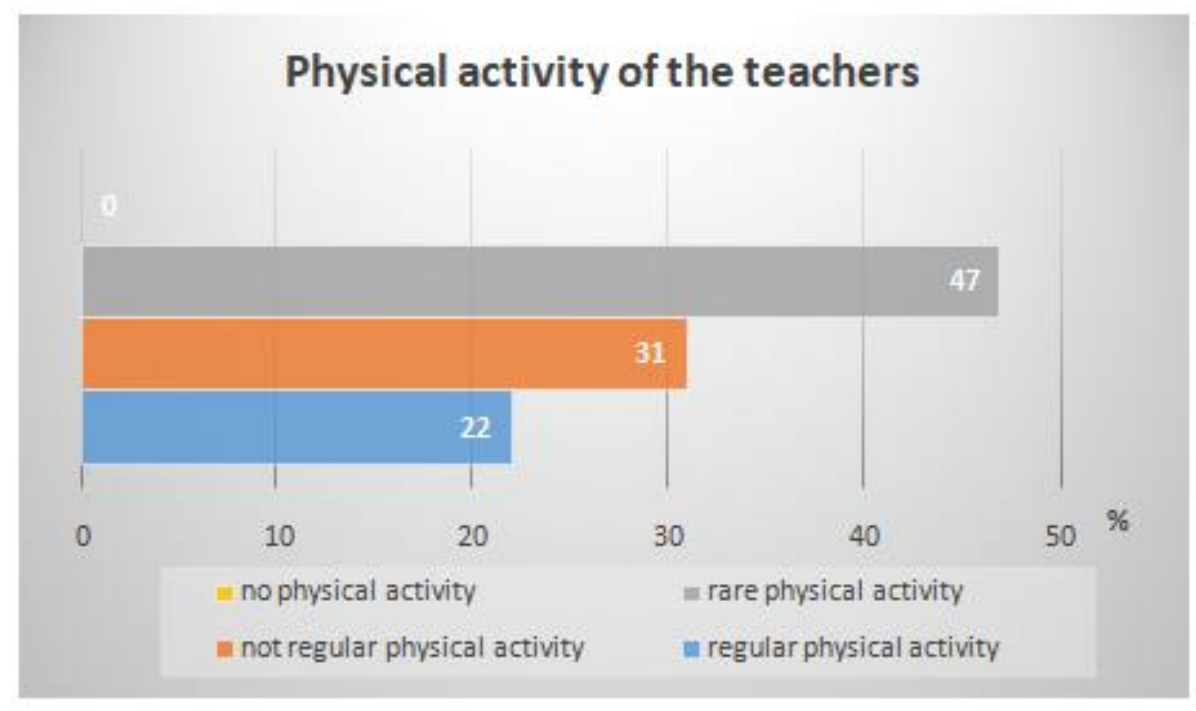

Fig3. Physical activity of the teachers

\section{CONCLUSION}

Our results suggest that the generalist teachers teaching PE can significantly influence the quality of PE delivered in schools. The crucial factors are the competence level of teachers teaching PE, 
cancelling or replacing the PE lessons by other subjects and teachers' attitude to sports and physical activity. We believe that the pre-service education as well as in-service provision of teachers should be very much targeted on the importance of physical activity of children and their motor development. It is also important to educate teachers in terms of their own fitness level and regular physical activity. It seems that regular physical activity of the teachers and their understanding of its importance could be an important factor affecting quality physical education in primary schools.

\section{ACKNOWLEDGEMENTS}

The authors do not have any potential conflicts of interest.

\section{REFERENCES}

[1] Antala, B. et al. Telesná a športová výchova a súčasná škola. Bratislava: NŠC a FTVŠ UK, 2004, ch. 2, pp 46-57.

[2] Bailey, R. Physical education and sport in schools: A review of benefits and outcomes, Journal of School Health, 76 (2006), 397-401.

[3] Haag, H. Philosophical and anthropological justification for physical education in and outside of schools. FIEP bulletin, Vol. 83, special edition No. 3 (2013), 216-218.

[4] Hardman, K. Worldwide survey on the state and status of physical education in schools: Foundations for deconstruction and reconstruction of physical education. In Hardman K., (Ed.), Physical Education : Deconstruction and reconstruction - Issues and directions (pp. 15-34). Schorndorf : Hofmann (2003).

[5] Malina, R.M. Motor development during infancy and early childhood: overview and suggested directions for research. International journal of sport and health science, 2 (2004), 50-56.

[6] Kwan, M.Y., Cairney, J., Faulkner, G.E., \&Pullenavegum, E.E.. Physical activity and other health-risk behaviours during the transition into adulthood: A longitudinal cohort study, American Journal of Preventive Medicine, 42(1), (2012), 14-20

[7] Rodney P. J. et al. Physical activity and quality of life among university students: exploring self-efficacy, self-esteem, and affect as potential mediators. Quality of Life, ResearchVolume 23, Issue 2 (2014), pp 659-667

[8] Scheuer, C. Holzweg, M. Quality in physical education: an overview from perspective of physical education teacher associations.Scheuer, C (Ed.). Physical Education: Quality in Management and Teaching. Berlin: Logos Verlag (2014).

Citation: Dana Masaryková, LenkaBobocká. "Quality Physical Education in Primary Schools from the Teachers' Point of View" International Journal of Sports and Physical Education (IJSPE), vol 7, no. 1, 2020, pp. 07-10. doi: https://doi.org/10.20431/2454-6380.0701002.

Copyright: () 2021 Authors. This is an open-access article distributed under the terms of the Creative Commons Attribution License, which permits unrestricted use, distribution, and reproduction in any medium, provided the original author and source are credited. 